\title{
Contribution to the knowledge of the $\mathrm{Cu}-\mathrm{Sn}-\mathrm{Zn}$ system for compositions close to brass alloys
}

\author{
C. Vilarinho*, D. Soares, F. Castro \\ University of Minho, Azurém, 4800-058 Guimarães, Portugal
}

Received 10 June 2003; received in revised form 16 February 2004; accepted 16 February 2004

\begin{abstract}
The effect of tin content in the equilibrium phases of the $\mathrm{Cu}-\mathrm{Zn}$-based alloys, within the range of chemical compositions with interest to brass producers is described. For this purpose, ternary alloys with copper contents between 55.4 and 67.5 wt.\% and tin contents up to $5.30 \mathrm{wt} . \%$ have been studied. The chemical composition of each alloy has been determined by X-ray fluorescence spectrometry (XRF). Isothermal homogenization, followed by rapid cooling, has been employed to determine the equilibrium phases at different temperatures. The homogenized alloys have been observed by scanning electron microscopy and the respective chemical analysis of the phases determined by electron probe microanalysis (EPMA). The statistical analysis of the obtained results enable to correlate the chemical composition of equilibrium phases with temperature. The chemical composition of the three-phase field, for the studied temperatures, has also been determined. (c) 2004 Elsevier B.V. All rights reserved.
\end{abstract}

Keywords: Metals; Casting; Scanning and transmission electron microscopy

\section{Introduction}

Tin is one of the common elements present in the composition of brasses (up to $1 \mathrm{wt} . \%$ in cast brasses) [1-3]. Although its presence improves the mechanical properties $[4,5]$ and the corrosion resistance, namely dezincification resistance, of brasses [2,5-8] its content should be selected as function of the requested properties because it promotes hot tearing in cast brasses [9-12].

According to Guillet, who first studied the influence of tin in brasses (1905), and most recently other researchers [13], the solubility of tin in $\alpha$ - and $\beta$-phases, of the $\mathrm{Cu}-\mathrm{Zn}$ system, is a function of zinc content. High tin contents are responsible for an eutectoid structure with the formation of a hard phase, $\gamma 1$, similar to $\delta$-phase of bronzes, as a consequence of the reaction $\beta \leftrightarrow \alpha+\gamma 1$ [1,3,14-17].

Isothermal sections of the phase diagram $\mathrm{Cu}-\mathrm{Sn}-\mathrm{Zn}$ have been constructed by several authors, but only Hudson and Jones [3], Bauer and Hansen [18] and Yamaguchi and Nakaruma [13] studied the alloys in the area of commercial brasses. Hudson et al. have drawn the isothermal section at

\footnotetext{
* Corresponding author.

E-mail address: candida@dem.uminho.pt (C. Vilarinho).
}

$425^{\circ} \mathrm{C}$ and presented the phase relationships at this temperature [3]. However, this isothermal section contradicted in some details with the phase rule [13]. Bauer and Hansen determined seven isothermal sections, using thermal analysis and metallographic techniques, in the compositions range of $50-70 \mathrm{wt} . \% \mathrm{Cu}$ and $0-7 \mathrm{wt} . \% \mathrm{Sn}$, from 800 to $400^{\circ} \mathrm{C}$, and established the boundaries for the three-phase field $\alpha+\beta+\gamma 1$ at 500, 450 and $400^{\circ} \mathrm{C}$ [18].

Yamaguchi and Nakamura [13] presented the isothermal sections for the range $0-40 \mathrm{wt} . \% \mathrm{Sn}$ and $0-50 \mathrm{wt} . \% \mathrm{Zn}$ at 600 and $550^{\circ} \mathrm{C}$, the results being in accordance with Bauer and Hansen [18]. In the present work, the equilibrium phases and its chemical compositions have been determined for copper contents between 55.4 and $67.5 \mathrm{wt} . \%$ and tin contents up to $5.30 \mathrm{wt} . \%$. The chemical compositions of the obtained equilibrium phases, at different temperatures, have been determined by EPMA.

\section{Experimental procedure}

Several $\mathrm{Cu}-\mathrm{Zn}$ alloys have been prepared by melting high purity copper and zinc ( $\geq 99.9 \%$ purity) in a medium frequency induction furnace $(3000 \mathrm{~Hz})$ and then were remelted for the addition of $\mathrm{Sn}$ in different contents. The cast alloys, 
Table 1

Chemical compositions of the alloys produced in this work (wt.\%)

\begin{tabular}{rccc}
\hline Alloy no. & $\% \mathrm{Cu}$ & $\% \mathrm{Zn}$ & $\% \mathrm{Sn}$ \\
\hline 1 & 59.6 & 40.5 & $<0.02$ \\
2 & 59.4 & 40.3 & 0.4 \\
3 & 59.3 & 39.9 & 0.8 \\
4 & 59.3 & 39.5 & 1.2 \\
5 & 67.5 & 32.5 & $<0.02$ \\
6 & 67.2 & 32.3 & 0.6 \\
7 & 67.0 & 32.1 & 0.9 \\
8 & 66.7 & 31.9 & 1.4 \\
9 & 66.7 & 31.5 & 1.8 \\
10 & 65.1 & 34.9 & 0.05 \\
11 & 64.9 & 34.5 & 0.6 \\
12 & 64.8 & 34.2 & 1.0 \\
13 & 64.8 & 33.9 & 1.3 \\
14 & 61.2 & 38.8 & $<0.02$ \\
15 & 61.2 & 38.5 & 0.3 \\
16 & 61.1 & 38.4 & 0.5 \\
17 & 61.0 & 38.2 & 0.8 \\
18 & 55.5 & 44.4 & 0.02 \\
19 & 56.6 & 39.6 & 3.8 \\
20 & 55.4 & 39.3 & 5.3 \\
\hline
\end{tabular}

all poured into a steel mould, presented a copper content in the range of 55.4-67.5 wt.\% and up to $5.30 \mathrm{wt} . \%$ of Sn. After the determination of their chemical composition, by X-ray fluorescence spectrometry (XRF), and the observation in optical microscope, specimens of each alloy were cut and homogenized at different temperatures, 750, 650, 550, 450 and $350{ }^{\circ} \mathrm{C}$ in a heat treatment furnace. To measure the temperature, a type $\mathrm{K}$ thermocouple, with an accuracy of $\pm 1.5^{\circ} \mathrm{C}$ was used. The samples were first heated up to $830^{\circ} \mathrm{C}$ and then slowly cooled $\left(2{ }^{\circ} \mathrm{C} \mathrm{min}^{-1}\right)$ to the homogenization temperature. In order to assure fully homogenization, the samples were submitted to a stage of $24 \mathrm{~h}$ after which they were rapidly quenched in a solution of salted water, with $50 \mathrm{~g} / 1$ $\mathrm{NaCl}$, and ice at $\sim 0{ }^{\circ} \mathrm{C}$.

After the homogenization experiments, the alloys were observed in a scanning electron microscope (SEM), JEOL JSM35C, and the chemical composition of the phases present in the microstructure determined by electron probe microanalysis (EPMA), CAMECA SX50.

\section{Results and discussion}

The chemical compositions of the alloys produced in this work, determined by XRF spectrometry, are presented in Table 1.

Accuracy of the determinations were $\pm 0.4 \%$ for copper and zinc and $0.02 \%$ for tin. No detectable amounts of other elements were found.

Besides the fact that the chemical compositions of the cast alloys corresponds to the range of brasses with commercial interest, it is clear from optical microscopy, that there are great differences in microstructure of the alloys. Hence, as a function of the chemical composition, the microstructure of
Table 2

Expressions, in the form of $(\% \mathrm{Sn})=A+B \times(\% \mathrm{Zn})$, determined by regression analysis indicating the chemical composition of the $\alpha$-phase in the two-phase field $(\alpha+\beta)$ at different homogenization temperatures

\begin{tabular}{lrlll}
\hline Temperature $\left({ }^{\circ} \mathrm{C}\right)$ & \multicolumn{1}{l}{$A$} & $B$ & $r^{2}$ & Equation no. \\
\hline 750 & 8.15 & -0.22 & 0.64 & $(1)$ \\
650 & 11.77 & -0.32 & 0.93 & $(2)$ \\
550 & 13.07 & -0.347 & 0.88 & $(3)$ \\
450 & 6.65 & -0.17 & 0.51 & $(4)$ \\
350 & 2.27 & -0.06 & 0.34 & $(5)$ \\
\hline
\end{tabular}

the as-cast alloys produced in this work might consist only of the $\alpha$-phase in dendritic form (Fig. 1(f)), the $\alpha+\beta$ phases (Fig. 1(c) and (d)), equiaxial grains of $\beta$-phase (Fig. 1(a)) and $\alpha+\gamma 1$ or $\beta+\gamma 1$ (Fig. 1(e) and (b)), respectively. When the $\gamma 1$-phase is present in the microstructure of the as-cast alloys, it is preferentially located at the grain boundary and/or at the interdendritic space (Fig. 1(b) and (e)).

For alloys with different tin contents, the homogenization experiments at different temperatures allowed the evaluation of the influence of the temperature on the equilibrium phases and their chemical compositions.

Employing a regression analysis technique, it has been possible to estimate several relationships that express the chemical composition of the equilibrium phases at different homogenization temperatures, for the two-phase field $(\alpha+\beta)$, as presented in Fig. 3. These relationships, presented in Table 2 for the $\alpha$-phase and in Table 3 for the $\beta$-phase, are expressed in the form of $(\% \mathrm{Sn})=A+B \times$ $(\% \mathrm{Zn})$. The respective correlation coefficients $\left(r^{2}\right)$ and the uncertainty levels corresponding to each expression are also presented.

The presence of the $\gamma 1$-phase has been detected at $550{ }^{\circ} \mathrm{C}$, in equilibrium with $\alpha$ - or $\beta$-phases, for the alloys no. 8 , 9 and 20. Three phases in mutual equilibrium have been detected at $450{ }^{\circ} \mathrm{C}$ only for alloys no. 19 and 20 and at $350^{\circ} \mathrm{C}$ for alloys no. 3, 4, 16, 17, 19 and 20. Fig. 2 illustrates the $\beta+\gamma 1$ and $\alpha+\beta+\gamma 1$ equilibrium for alloy no. 20 after homogenization at $550^{\circ} \mathrm{C}$ (Fig. 2(a)) and at $450^{\circ} \mathrm{C}$ (Fig. 2(b)). Table 4 presents the chemical composition of the three-phase field at $450{ }^{\circ} \mathrm{C}$, for this alloy.

A multivariant regression analysis allowed the determination of the influence of the temperature on the chemical composition of the equilibrium phases in the three-phase field.

Table 3

Expressions, in the form of $(\% \mathrm{Sn})=A+B \times(\% \mathrm{Zn})$, determined by regression analysis indicating the chemical composition of the $\beta$-phase in the two-phase field $(\alpha+\beta)$ at different homogenization temperatures

\begin{tabular}{lllll}
\hline Temperature $\left({ }^{\circ} \mathrm{C}\right)$ & $A$ & $B$ & $r^{2}$ & Equation no. \\
\hline 750 & 26.55 & -0.65 & 0.95 & $(6)$ \\
650 & 29.56 & -0.70 & 0.98 & $(7)$ \\
550 & 32.26 & -0.74 & 0.99 & $(8)$ \\
450 & 29.44 & -0.65 & 0.97 & $(9)$ \\
350 & 31.11 & -0.69 & 0.90 & $(10)$ \\
\hline
\end{tabular}




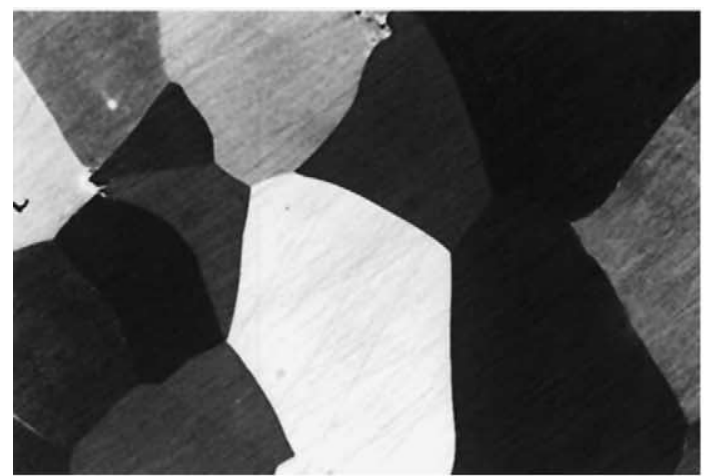

(a) Alloy $n^{\circ} 18$

$\longmapsto$

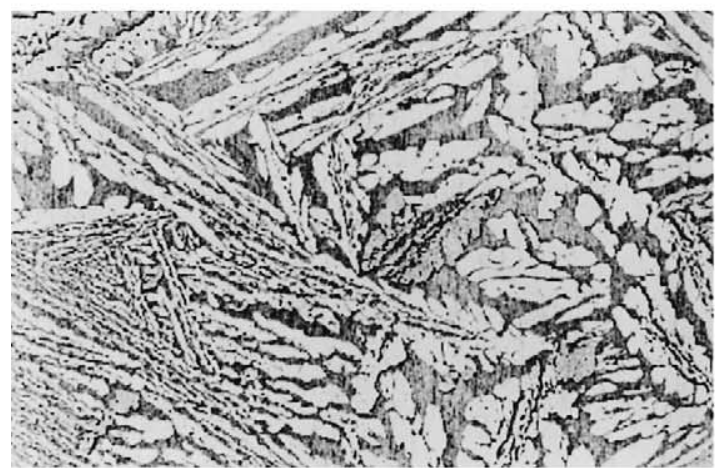

(c) Alloy $\mathrm{n}^{\circ} 2$

$\stackrel{200 \mu \mathrm{m}}{2}$

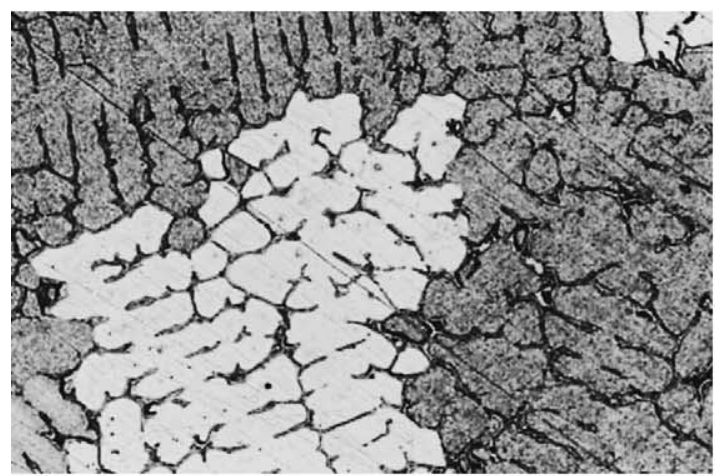

(e) Alloy $n^{\circ} 9$

$\stackrel{200 \mu \mathrm{m}}{2}$

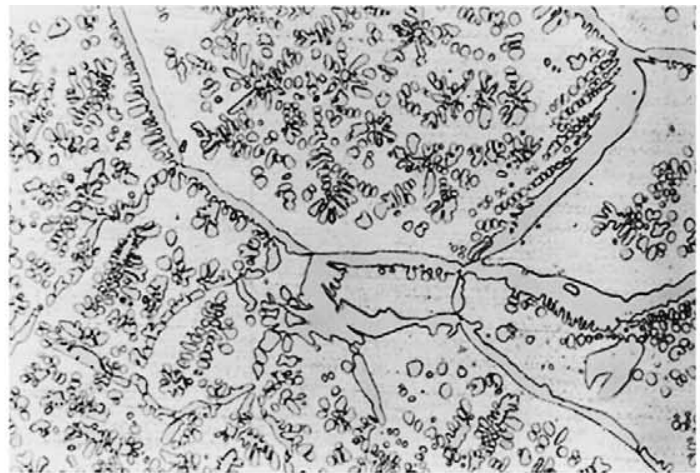

(b) Alloy $\mathrm{n}^{\circ} 20$

$\stackrel{\longmapsto}{\longmapsto 00 \mu \mathrm{m}}$

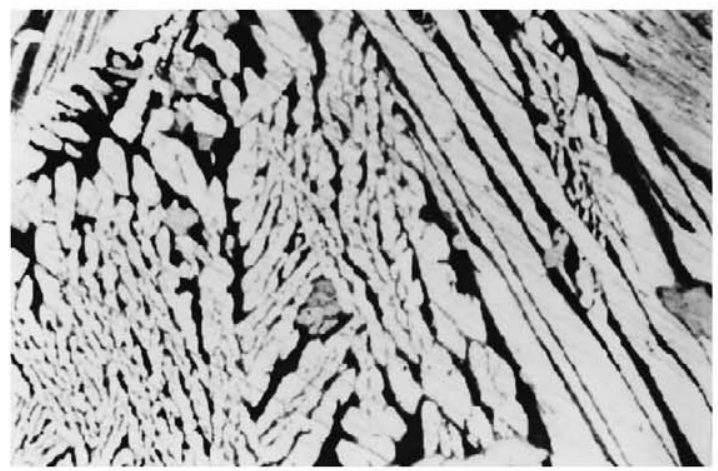

(d) Alloy $n^{\circ} 17$

$\longmapsto$

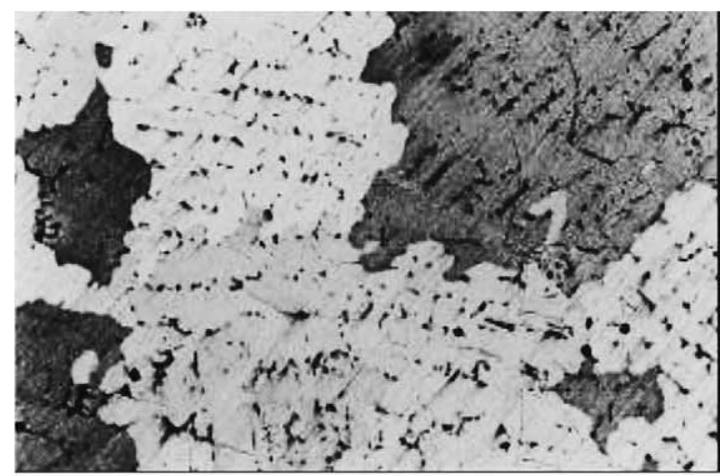

(f) Alloy $n^{\circ} 10$

$\underset{100 \mu \mathrm{m}}{\longmapsto}$

Fig. 1. Microstructure of as-cast alloys with different $\mathrm{Cu} / \mathrm{Zn}$ ratios and $\mathrm{Sn}$ contents $(100 \times)$.

Table 4

Chemical compositions of equilibrium phases in the three-phase field domain, determined by EPMA, after homogenization experiments at $450^{\circ} \mathrm{C}$, for alloy no. 20

\begin{tabular}{lllr}
\hline & $\% \mathrm{Cu}$ & $\% \mathrm{Zn}$ & \multicolumn{1}{c}{$\% \mathrm{Sn}$} \\
\hline$\alpha$ & $62.4( \pm 0.3)$ & $37.1( \pm 0.3)$ & $0.54( \pm 0.00)$ \\
$\beta$ & $56.4( \pm 0.1)$ & $41.0( \pm 0.1)$ & $2.61( \pm 0.01)$ \\
$\gamma 1$ & $51.3( \pm 0.4)$ & $36.6( \pm 0.3)$ & $12.13( \pm 0.09)$
\end{tabular}

The measured chemical composition of the $\gamma 1$-phase, for different alloys and in the range of temperatures between 450 and $350^{\circ} \mathrm{C}$, was almost constant $(\mathrm{Sn}=11.84 \mathrm{wt} . \%$ $( \pm 1.03)$ and $\mathrm{Zn}=37.0 \mathrm{wt} . \%( \pm 1.5))$. No correlation has been determined between the chemical composition of this phase and the temperature. This evidence is not in accordance with the results obtained in previous works $[13,18]$, which presents different values for the chemical composition of the $\gamma 1$-phase and its variation with temperature.

Although the tin content of the $\alpha$-phase slightly decreases with the decreasing temperature $\left(\% \mathrm{Sn}=1.12 \times 10^{-3} \mathrm{~T}\right.$ 


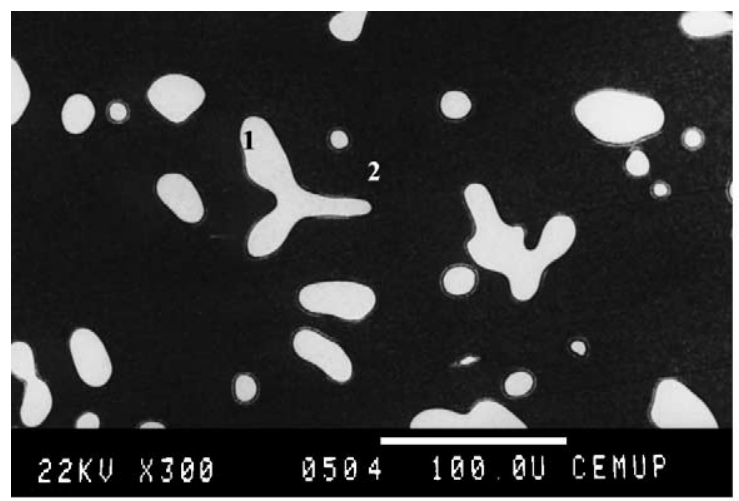

(a)

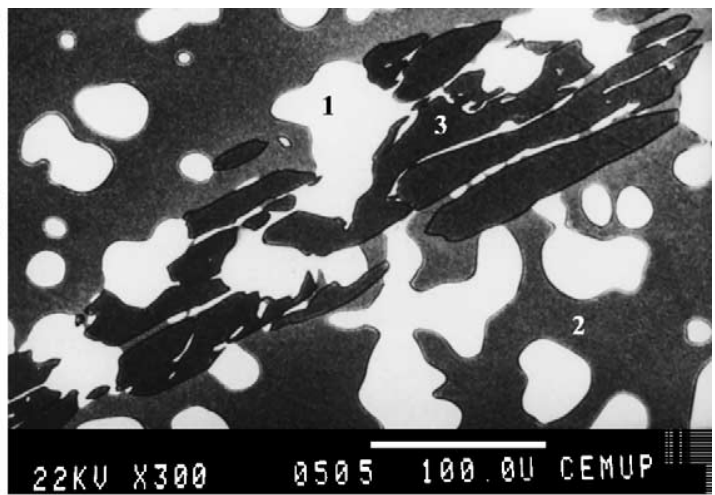

(b)

Fig. 2. Equilibrium phases for the alloy no. 20 after homogenization at $550^{\circ} \mathrm{C}$ (a) and $450{ }^{\circ} \mathrm{C}$ (b) $-1, \gamma 1 ; 2, \beta ; 3, \alpha$.

$( \pm 0.21))$, which is in accordance with the literature, the same conclusion is not accomplished for the zinc content of this phase [18]. For that reason, the zinc content of the $\alpha$ vertice of the three-phase field has been considered constant and equal to the average content $(\% \mathrm{Zn}=36.8( \pm 0.7))$.

Concerning the chemical composition of the $\beta$-phase, in the three-phase field, it strongly changes with temperature, both in tin $\left(\% \mathrm{Sn}=-1.67( \pm 0.45)+9.38 \pm 10^{-3} T\right)$ and zinc $\left(\% \mathrm{Zn}=52.1( \pm 0.6)-2.44 \times 10^{-2} T\right)$ contents. However, the solubility values of $\mathrm{Sn}$ and $\mathrm{Zn}$ in the $\beta$-phase are not in accordance with those presented in the literature.

Fig. 3(a) compares the results obtained in this research, concerning the three-phase field, with those obtained in pre-

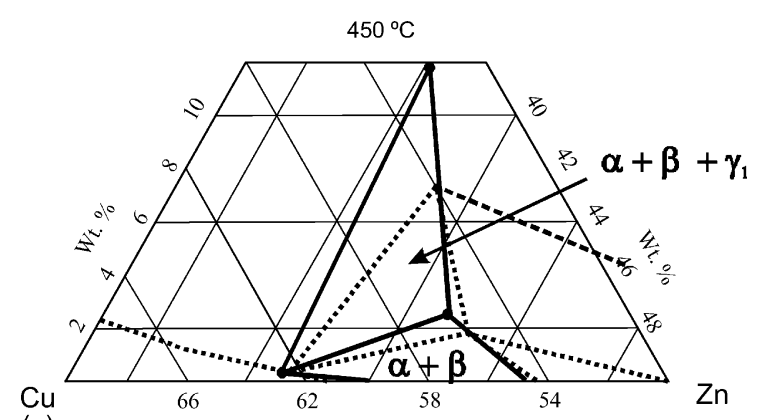

(a)

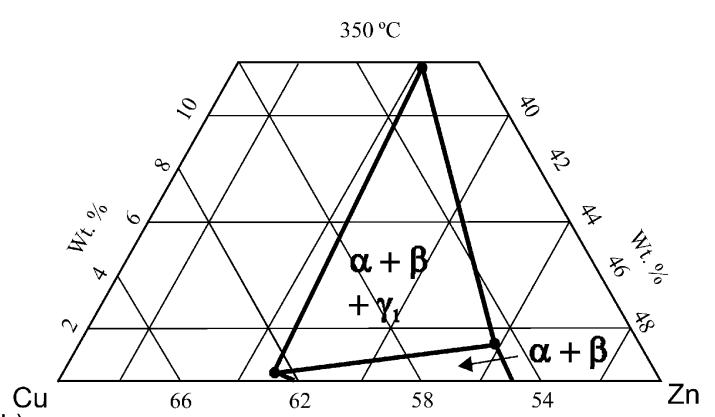

(b)

Fig. 3. (a) Isothermal section at $450^{\circ} \mathrm{C}$ proposed by Bauer and Hansen (dashed line) [18] and points calculated by statistical treatment of the results obtained in homogenization experiments (solid line); (b) isothermal section at $350^{\circ} \mathrm{C}$ calculated by statistical treatment of the results obtained in homogenization experiments. vious investigations for $450^{\circ} \mathrm{C}$ and Fig. 3(b) presents the same field for $350{ }^{\circ} \mathrm{C}$ which was previously unknown.

In previous studies the existence of a three-phase was reported to extend up to $550{ }^{\circ} \mathrm{C}$. In the chemical compositions range studied in this work, these results could not be confirmed: no three-phase range was observed by us at $500{ }^{\circ} \mathrm{C}$.

\section{Conclusions}

The results obtained in this work enabled the establishment of several relationships that indicated the effect of the tin content of brasses on the chemical composition of the equilibrium $\alpha$-, $\beta$ - and $\gamma 1$-phases, at different temperatures. The results show that the chemical composition of the equilibrium phases in the three-phase field, at $450{ }^{\circ} \mathrm{C}$, are different from those proposed in other published works and a new phase field region was established for the $\alpha+\beta+\gamma 1$ phases at this temperature. The Sn solubility in the $\gamma 1$-phase obtained in this work is higher than the values proposed in the literature. This could be explained by the use of a more accurate technique to determine the chemical composition of equilibrium phases at different temperatures. The range of temperatures covered in this research allowed also the determination of equilibrium data for the temperature of $350{ }^{\circ} \mathrm{C}$, which was previously unknown. At $550^{\circ} \mathrm{C}$ no three-phase field was found.

\section{References}

[1] A. French, J. Inst. Met. 85 (1956-1957) 293-315 (in English).

[2] P.-J. Le Thomas, D. Arnaud, Fonderie 162 (1959) 323-325 (in French).

[3] O. Hudson, R. Jones, J. Inst. Met. 14 (1915) 98-115 (in English).

[4] H. Rosenthal, Principles of Metal Casting, 2nd ed., McGraw-Hill, New York, 1967 (in English).

[5] G. Bengough, R. May, J. Inst. Met. 32 (1924) 81-265 (in English).

[6] V. Loconsolo, L. Nobili, Manuale Degli Ottoni, $1^{\text {a }}$ ed., Consedit, Milano, 1995, 172 pp. (in Italian). 
[7] D. Davies, A Note on the Dezincification of Brass and the Inhibiting Effect of Elemental Additions, Copper Development Association, New York, 1993, 9 pp. (CDA, Technical Report) (in English).

[8] L. Ramanathan, Corrosão e seu controle, Hemus, São Paulo, 1982 (in Portuguese).

[9] A. Louvo, T. Rantala, V. Rauta, Proceedings of the 51st International Foundry Congress on the Effect of Composition on As-cast Microstructure of $\alpha+\beta-$ Brass and its Control by Microcomputer, Lisboa, 1984 (in English).

[10] F. Castro, J. Junqueira, Latões para fundição, Barcelos: Edição de CETEM, Centro Técnico de Engenharia Mecânica, Metalúrgica e de Materiais, Cadernos de Metalurgia, no. 3, 1996. ISBN 972-9457-03-4 (in Portuguese)
[11] H. Boswinkel, Shrinkage and hot tearing of permanent mold cast brass, AFS Cast Met. Res. J. (1972) 110-113.

[12] H. Boswinkel, The British Foundryman, May (1971) 173-191.

[13] K. Yamaguchi, I. Nakamura, Inst. Phys. Chem. Res. Tokyo 11 (1933) 1330-1352.

[14] Weels, Copper and Copper Alloys, McGraw-Hill, 1982.

[15] J. Haworth, W. Hume-Rothery, Phil. Mag. 43 (1952) 613-629 (in English).

[16] W. Campbell, Proc. Am. Soc. Test. Met. 20 (11) (1920) 104-114.

[17] S. Hoyt, P. Brinton, J. Inst. Met. 14 (2) (1915) 178-188.

[18] O. Bauer, M. Hansen, Z. Metallkd. 22 (12) (1930) 405-411 (in German). 